\title{
DOCUMENTO
}

\section{¿Dónde se juega la justicia en nuestro entorno en los próximos diez años?}

\section{Luis de Sebastián'}

\begin{abstract}
El 26 de mayo de 2009 ha fallecido en Vilanova i la Geltrú (Barcelona) Luis de Sebastián y Carazo. Muchos eran los lazos que unieron a Luis de Sebastián con la Revista de Fomento Social. En ella sus ideas encontraron acogida, tres veces se publicaron textos suyos: en 1997, 2000 y 2002. Si el primero se refería al euro (Revista de Fomento Social 52 (1997) 517-534) y el último al modelo económico del gobierno Aznar (Revista de Fomento Social 57 (2002) 101-113), el que volvemos a publicar ahora tiene un carácter más actual, pues aunque el título, "¿Dónde se juega la justicia en nuestro entorno en los próximos diez años?", se refiera a los problemas de la justicia en los diez años que están terminando, leído ahora nos damos cuenta de que esos problemas no sólo no han sido superados, sino que algunos continuamente siendo muy actuales.
\end{abstract}

Con ocasión de la muerte de Luis de Sebastián se publicaron varias notas que hemos visto, en la prensa diaria: Josep F. MÀRIA S.I., "Intelectual por la justicia" en El País; Carlos LOSADA, "Un profesor de lujo" en La Vanguardia, ambas el 27 de mayo de 2009; Alfred VERNIS, "Un humanista en la economía" en Cinco días el 29 de mayo de 2009. A ellas remitimos a nuestros lectores. Luis de Sebastián había estudiado en los siguientes centros universitarios: Berchmanskolleg de Munich, Graduate Institute of International Studies de la Universidad de Ginebra, London School of Economics, así como en las universidades de Barcelona, Londres y Gregoriana de Roma; durante años perteneció a la Compañía de Jesús. Fue profesor en la Universidad Centroamericana de El Salvador y en ESADE de Barcelona. En el momento de fallecer era catedrático emérito de la Universidad Ramon Llull de Barcelona. De sus obras destacamos: Mundo rico, mundo pobre. Pobreza y solidaridad en el mundo de hoy (Santander 1992) La solidaridad. "Guardián de mi hermano" (Barcelona 1996), Neoliberalismo global: apuntes críticos de economía internacional (Madrid 1997), Los diez mandamientos: una versión secular (Barcelona 1998),

\footnotetext{
' Catedrático de ESADE - Universidad Ramon Llull, Barcelona.
} 
La crisis de América latina y la deuda externa (Madrid 1988), El rey desnudo. Cuatro verdades sobre el mercado (Madrid 1999), De la esclavitud a los derechos humanos. La formación del pensamiento solidario (Barcelona 2000), Capitalismo y democracia en el siglo XXI. Nuevas tendencias y nuevos destinos (2000), Un mundo por hacer: claves para comprender la globalización (Madrid 2002), Los diez mandamientos del siglo XXI (Barcelona 2002), Razones para la esperanza en un futuro imperfecto (Barcelona 2003), Pies de barro. La decadencia de los Estados Unidos de América (Barcelona 2004) África, pecado de Europa (Madrid 2006), Un planeta de gordos y hambrientos. La industria alimentaria al desnudo (Barcelona 2009).

Mis amigos jesuitas me han hecho esta pregunta, esperando sin duda que les pueda iluminar con mi opinión sobre estas cosas. Mis opiniones les doy con todo cariño y entusiasmo. Son opiniones sobre lo que hay que hacer en el futuro. Hay que empezar, cuanto antes, claro, pero lo que propongo son cosas que requerirán la constancia y perseverancia que sin duda tiene en abundancia el colectivo de jesuitas a que me dirijo. Son sólo opiniones y sugerencias, algunas difíciles de documentar y de razonar convincentemente, pero razonables y según mi intuición, cada vez más importantes para el futuro. Al desarrollar estas ideas en nuestro encuentro trataré de razonarlas mejor.

\section{La seguridad social}

No dejar a los mayores desprotegidos, antes bien crear estructuras para atenderles. En los próximos años se va a dar una fuerte batalla para la reforma del sistema de pensiones, porque el interés en ello de las empresas financieras es muy grande. Administrar los ahorros de toda la población les supone un negocio muy atractivo. Es verdad que la evolución de la población, que lleva a casi invertir la pirámide de edades, plantea un problema real al sistema actual de pensiones. Pero hay que buscar soluciones desde la voluntad de mantenerlo substancialmente, aunque todo el mundo tenga que hacer algún sacrificio (retrasar la edad de jubilación, aportar algo más los beneficiarios mismos, aumentar impuestos, reducir algunos niveles de prestaciones, etc.)

Las alternativas que se proponen, fondos privados de pensiones (la solución chilena que José Pinera ha venido a predicar en España) lleva a profundas diferencias sociales, que además no están probadas. La propuesta que hizo al Círculo de Empresarios consistiría en que todas las personas menores de 45 años hicieran una contribución obligatoria a un fondo privado de jubilación, administrado por 
la empresa financiera que cada cual escogiera. Esas personas dejarían automáticamente de aportar a la caja común de la Seguridad Social (pública), de donde, en el actual sistema, se sacan los pagos de pensiones. Lo cual implica que durante muchos años el estado tendría que hacer aportes substanciales a esa caja común o fondo público para poder seguir pagando pensiones. Habría que aumentar los impuestos y correr un déficit fiscal considerable. El fondo mantendría, o aumentaría su valor (que es lo que siempre se supone) según los rendimientos de los activos en que se invierta el fondo. En un período de vida largo es probable que las acciones hayan aumentado bastante de valor, y los bonos del estado hayan mantenido un rendimiento razonable, aunque menor que las anteriores. Pero eso no garantiza que en un momento dado, el valor del fondo sea suficiente para asegurar al jubilado una vida decente. Además, ¿̇qué pasa con los que tienen empleos intermitentes y pasan largos periodos desempleados? Obviamente se debe asegurar un mínimo a quienes han tenido mala suerte. El sistema solo se ha introducido en países donde se pagan pocas pensiones y no está probado.

La solución del problema de las pensiones tiene siempre una dimensión de futuro y un problema generacional. Hay que pensar en dar soluciones a los problemas de la gente mayor que no perjudique las oportunidades de los que ahora son niños y un día lejano serán jubilados, los viejos del futuro, como sería con un exceso de deuda pública que siempre acaba en impuestos futuros.

\section{La emigración}

La emigración de los seres humanos es un movimiento zoológico y económico imparable, que existe en todo el reino animal, y que en el humano ha habido siempre y seguirá habiendo, mientras con ella los individuos y los pueblos tengan - o crean tener - la posibilidad de mejorar sus condiciones de vida. Es un fenómeno de fuerza cósmica imparable una vez que se pone en marcha en una dirección determinada. Aumenta en relación directa al número de personas provenientes de países pobres establecidas en el país de destino (Lo que se conoce como efecto llamada).

Es además un fenómeno necesario en la España del siglo XXI para mantener en pie la estructura productiva de España en un período de 10 años a 20 años, dado la dinámica de la población española. (Después las innovaciones tecnológicas pueden cambiar los términos de la ecuación)

Por lo tanto la emigración puede resultar beneficiosa tanto para los emigrantes que encuentren trabajo y se integren en la sociedad española, como para quienes se 
benefician de su trabajo (empleadores y seguridad social). En este sentido hay que tratar de considerar a la migración y presentarla como algo positivo y constructivo, no como una amenaza o un problema, aunque, lógicamente, la forma concreta como se realiza puede generar problemas de rechazo mutuo, que se manifiestan en agresividad y discriminación por una parte y en anomia, agresividad o marginación voluntaria por la otra.

Es un hecho que la represión de la migración ilegal crea "precios de escasez" (para el paso del Estrecho, por ejemplo, o para cruzar el Río Grande) y por lo tanto incentivos para quienes organizan los flujos migratorios (los tour operators o coyotes) La organización de estos flujos ha contribuido enormemente a posibilitar la aventura, que una persona no se atrevería a emprender por sus propios medios. La endiablada lógica económica de la represión lleva a la corrupción entre las autoridades que controlan el sistema.

España tiene todavía mucha capacidad de recibir emigrantes. Menos del $1 \%$ de los censados han nacido fuera de España. Y de este $1 \%$, la mitad son ciudadanos de la UE, jubilados o retirados, establecidos en las costas del Sur o de las Baleares y las Canarias. En Alemania casi el $6 \%$ de los censados han nacido fuera del país y en Estados Unidos casi el $12 \%$ de los censados han nacido fuera. El hecho de que los emigrantes se concentren en algunos puntos, como Almería, el Maresme, - las grandes ciudades, Madrid y Barcelona, puede dar la impresión de que hay muchos, pero no es así.

Pero la población tiene que ser educada para recibir a los emigrantes en términos de igualdad y convivir con ellos como ciudadanos del mismo estado. El racismo todos lo llevamos dentro, como un mecanismo más de auto-protección contra lo desconocido y lo diferente. Ese instinto primario tiene que ser controlado y dominado por medio de la educación, una educación que quite el miedo a lo desconocido y exalte la riqueza que hay en la variedad y la diferencia entre razas y pueblos. Naturalmente, a los emigrantes hay que educarlos también para que sepan convivir y comportarse en una cultura que le es extraña, a lo cual contribuiría mucho que les tratemos como ciudadanos de primera

Por otra parte, no cabe duda de que los flujos migratorios tienen que ser ordenados de alguna manera sensata y humana, para que los emigrantes no caigan en la marginación y sean perseguidos. El aprendizaje de la sociedad no es instantáneo. El proceso de aceptación por parte de la sociedad receptora y el de integración en ella requiere tiempo. Nos queda mucho por aprender en esta cuestión. 


\section{El empleo}

No se puede olvidar que el trabajo es un derecho constitucional, porque es la base de los ingresos necesarios para vivir, del progreso personal y de la integración social. La obligación de quienes juraron la Constitución al asumir el cargo de gobierno sigue estando en vigor también en este artículo. El pleno empleo (como se suele definir normalmente) debe seguir siendo un objetivo prioritario de la política económica y social del gobierno, sea cual sea el modelo económico que adopte. Porque no puede adoptar un modelo que lleve inherentemente el rechazo al pleno empleo.

Sin embargo, cualquier tipo de trabajo no cumple este derecho y esta función social. Una simple estadística, un 3 ó 4 \% de la fuerza de trabajo, puede no representar el cumplimiento del mandato constitucional. No basta la cantidad, hay que insistir en la calidad de los empleos que existen y los que se crean. Los empleos necesitan unos ciertos parámetros de aceptabilidad, en cuanto a la duración, a la remuneración, la posibilidad de aprender y de progresar, las condiciones materiales que constituyen el entorno del trabajo, etc. Se debe tratar de conseguir un pleno empleo de calidad

La falta de empleo afecta especialmente a los jóvenes y las mujeres, y esto no cambiará si no se toman medidas de fomento del empleo y de formación para el trabajo focalizadas a estos grupos. Se ha hecho en muchos países y se puede hacer en el nuestro. Se ha visto, por ejemplo, en Holanda y en otras partes que el trabajo a tiempo parcial (cuatro o cinco horas al día) beneficia mucho a las mujeres porque hace posible que combinen la atención a su hogar, hijos, etc. con el trabajo remunerado fuera del hogar.

Como no se puede ignorar los cambios que la tecnología, y la nueva economía que de ella ha surgido, han llevado a cabo en las condiciones y el concepto mismo de trabajo estable, hay que repensar el concepto de estabilidad en el trabajo. Lo que se necesita en el fondo no es tanto que no haya cambios de empleo, cuanto que en medio de tantos cambios se dé la posibilidad estable o permanente de encontrar trabajo, y la capacidad de adaptarse a él. Lo cual obliga a la sociedad que quiera disponer de posibilidades estables de empleo a trabajar en la capacitación permanente de los trabajadores para utilizar con provecho las nuevas tecnologías e incluso encontrar nichos para el autoempleo en la nueva economía. En dos palabras, capacitar para seguir aprendiendo 
Probablemente también haya que reorganizar los sistemas del subsidio de desempleo, para eliminar abusos, hacerlo más flexible y adaptarlo a las necesidades de la nueva situación del empleo. En todo caso hay que seguir preocupándose y gastando recursos para renovarse y disponer de un buen servicio de ayuda a los desempleados. Y finalmente quizá habría que estudiar en serio la posibilidad de implantar la renta ciudadana que ya existe en algunas partes.

\section{El acceso al crédito}

El acceso al crédito es importante para insertarse en la economía productiva y en la sociedad de consumo. El crédito bien usado es un instrumento de progreso económico, porque permite anticipar ingresos futuros para aprovechar oportunidades presentes, y de madurez personal, porque induce al cálculo racional y a un comportamiento prudente en cuestiones económicas. Pero muchas personas, especialmente los jóvenes, no pueden adquirir viviendas por medio de hipotecas, porque la vivienda es cara, su empleo es precario y en definitiva no son sujetos de crédito. Otros en cambio son sujetos de crédito, aunque hayan protagonizado malversaciones y estafas. En esto la sociedad es muy injusta.

Por su parte, las pequeñas empresas necesitan crédito para modernizarse y competir, en una nueva economía de innovaciones tecnológicas que requiere inversiones en equipos relativamente costosos. El crédito hace posible las inversiones rentables que aseguren la supervivencia de las empresas pequeñas y aun medianas. Pero, de nuevo, muchas pequeñas empresas no acceden a los créditos industriales que, sin embargo, se prodigan a las grandes, aun a las peor administradas. Por no mencionar a los trabajadores autónomos, albañiles, taxistas, pintores, escritores, etc. que no tienen niveles de facturación como para abrir las puertas de los bancos.

En resumidas cuentas, se necesita un sistema de crédito social, que puede ser paralelo o puede estar integrado como agencia especializada en el sistema de crédito normal. En nuestros días se habla mucho de las microfinanzas y de los créditos a las personas de bajos ingresos. Hay nuevas experiencias, como el Grameen Bank, o Banco de los Pobres, en Bangladesh, copiado con mayor o menor éxito en otros países en vías de desarrollo. Esos bancos han recogido y puesto al día algunas ideas antiguas ya probadas y experimentadas entre nosotros, como las cooperativas de crédito, que ahora convendría renovar y mejorar. Se podría, por ejemplo, hacer regresar a sus orígenes a las cajas de ahorro, que ya juegan a grandes bancos y que están a punto de desaparecer enterradas en una hipocresía institucional increíble 


\section{La economía dual (aumento de la desigualdad)}

El mundo se mueve, in virtud del proceso de mundialización, hacia un sistema de organización económica dual, con unos cuantos ciudadanos (y ciudades, regiones y países) muy ricos y poderosos, los ganadores de la mundialización, y otros muchos con una economía precaria, incierta, de bajo nivel y sin esperanza.

No es cierto que el mero crecimiento, sin redistribución de la riqueza, pueda cubrir esta brecha. Lo que se llama a veces "efecto rebalse" (trickle down en inglés), o las migajas de Zabulón, si preferís. Este efecto, si funciona en absoluto, funciona a largo plazo, a 20 o 30 años, y no por si mismo, sino que siempre ha necesitado el empuje y la dirección de la mano visible de un estado propenso a la redistribución de la riqueza. Esa es la historia de la prosperidad de los países del sudeste asiático, los tigres asiáticos que se suelen poner como ejemplo de desarrollo de países pobres.

De no hacerse nada para atajar el avance de la desigualdad, el mundo corre hacia un apartheid universal, en el cual los ricos y los pobres estarán física y geográficamente separados. Pero con una hostilidad mutua y guerra sorda entre ellos, probablemente implícita y no declarada, en forma de criminalidad, organizada o no, inseguridad ciudadana, asalto de sus fronteras (emigración), difusión de enfermedades, tráfico de drogas, por un lado, y nuevas cárceles y represión por otra.

Podemos deducir de los datos del presente, debidamente extrapolados, algunos fenómenos preocupantes del futuro inmediato que pueden derrumbar nuestra confianza en el mundo que hemos creado los países ricos. Los habitantes del mundo pobre tratando, cada vez con más osadía y desesperación, de pasarse al mundo rico, puede ser un ejemplo. Se darán nuevas formas de protesta, individual u organizada, de los excluidos de los beneficios de la mundialización, como nuevas revoluciones locales, basadas en la tecnología (exportación de viruses, secuestros, bombas, atentados terroristas, ¿̇qué sé yo?)

\section{La solidaridad internacional (¿qué hacemos con los pueblos pobres?)}

Puestos a pedir apasionadamente cambios para eliminar la pobreza en el mundo, debiéramos pedir, además de la condonación total de la deuda externa actual para 
los 50 ○ 60 países más pobres del mundo -que no estén en plena guerra civil-, hace falta establecer un mecanismo financiero para proveer a los países pobres de capital a largo plazo, dado que ellos tienen un ahorro interno muy pequeño e insuficiente para financiar el desarrollo, para que no vuelvan a incurrir en el actual nivel de endeudamiento al cabo de cinco años. Hay que combinar la condonación con la posibilidad de seguir recibiendo capital. No es fácil conceptual ni institucionalmente.

Apertura completa y sin condiciones de los mercados de los países ricos a todos los productos que sean capaces de vendernos, aunque hagan competencia a productos semejantes que producimos en nuestros países, como textiles, calzado, juguetes, muebles, etc. (muchos de los que protestaban en Seattle y Praga no estarán de acuerdo) Esto no es un argumento para una comercio indiscriminadamente libre, una liberalización comercial simétrica, sino para una apertura a simétrica, una acción afirmativa, para abrir los mercados de los países ricos a las mercancías de los países pobres, azúcar, por ejemplo.

La transformación de los préstamos blandos, o concesionales, en régimen bilateral, lo que constituye la mayor parte de la llamada ayuda al desarrollo, en donaciones puras y simples. Es decir, en transferencias que no generen deuda externa. Esas donaciones debieran ser de libre disposición y no atadas al uso de los recursos en compras y contratos en el país donante.

Medidas para hacer ilegal la venta de armas a países con conflictos bélicos, declarados o latentes, y regular seriamente (sin la hipocresía actual) el comercio ordinario de armas.

Ayuda médica en gran escala, cambiando para esos países los términos del comercio de medicinas, proporcionando asistencia con equipos, transporte y personal sanitario de todos los niveles.

Presiones internacionales para reducir, y eliminar si fuera posible, el mal gobierno de muchos de los países pobres, lo que exigiría a los países ricos, y sobre todo a sus empresas establecidas en aquellos, no contribuir a la corrupción de los funcionarios y gobernantes de esos países.

Asegurar que las empresas multinacionales practican en ellos una política de buena vecindad, y no se portan éticamente peor de lo que se portan en sus países de origen, donde las regulaciones y las leyes se hacen cumplir. Con la debida atención a todos los stakeholders (involucrados) en las operaciones de las empresas. 


\section{La justicia (Sistema judicial y penal)}

Me refiero aquí a los aspectos económicos de la justicia solamente. El ejercicio de los derechos ciudadanos que todos tenemos cuesta dinero, de manera que cuanto más dinero tiene un ciudadano mejor uso puede hacer, en su favor, de los derechos que protegen a todos los ciudadanos en un estado de derecho. $Y$ no es porque los derechos se compran o se vendan, ni porque suponga jueces $y$ administradores corruptos, sino simplemente porque el uso de las instituciones, no se hace en el vacío, sino que requiere la movilización de recursos y de personas, lo cual cuesta dinero.

Esto se ve clarísimamente en el ejercicio de la justicia, donde, por ejemplo, el apelar sucesivamente contra una sentencia condenatoria cuesta mucho dinero contratando abogados, pagando fianzas, consiguiendo el trato óptimo que el sistema penal permite a los reos etc. todas ellas son acciones que requieren el uso de recursos. Si esto es así, se sigue que los ricos tienen mayor capacidad de aprovecharse de la justicia que los pobres, lo que da pie a que se diga que la justicia es una justicia de ricos. Y en algún sentido es verdad, aun en el país donde funcione mejor. Hace falta una justicia ciega al dinero, que no sea de ricos ni de pobres, que sea de todos los ciudadanos y que todos tengan acceso a los muchos y sucesivos recursos que prevé el derecho.

Para acercarnos a ello, haría falta que, así como hay abogados de oficio, se estableciera un fondo social, o de oficio, para pagar abogados, depositar fianzas y subsidiar los costos en general de usar el sistema judicial.

Obviamente, lo que decimos de la justicia se puede aplicar a todo el mundo de producción y distribución de los bienes públicos, como el conseguir subvenciones, el trazado de las obras públicas, la construcción de aeropuertos y de puertos deportivos.

\section{Los colectivos marginados}

Con la creciente prosperidad también parece crecer el deshecho de la sociedad, los marginados. El sistema utiliza y consume seres humanos para crecer, pero a algunos los arroja a la calle, cuando no son útiles ni provechosos al sistema. Este es el origen principal de la marginación. Muchos de los que hoy son marginados no lo serían en un sistema económico distinto, con una organización social más justa y solidaria. Los emigrantes, por ejemplo, si hubieran nacido en un mundo 
más equitativo en la inversión y el comercio y su país se hubiera desarrollado más, no estarían en nuestras calles buscando algo para malvivir. Y los campesinos desplazados de sus campos, los enfermos despedidos de los asilos, los drogadictos no tratados, etc.

Por eso es razonable y justo considerarlos como víctimas de una mala organización que hemos dado a nuestra sociedad. No es siempre culpa suya. Normalmente su condición y situación es culpa del sistema, y remediarlo es responsabilidad de este. Los desempleados de larga duración son un claro ejemplo. Muchos de ellos, los más mayores e inempleables han acabado siendo marginados. No son marginados por no saber o querer trabajar, sino porque a una cierta edad nadie les emplea.

Hay que detectar las nuevas formas de marginación que se puede dar en nuestro medio. Quizá tengamos que ocuparnos de los marginados de la tecnología, por ejemplo, de quienes no tienen acceso a los ordenadores y a recibir la formación básica para utilizarlos, de los analfabetos del Internet. Quizá...

Por todo lo dicho creemos que las administraciones públicas son las primeras y principales responsables de resolver las complejas situaciones en que se ven los marginados, bien sea directamente bien sea indirectamente financiando a otros que lo hacen. Sin embargo, no se puede dejar toda la atención de los marginados a organizaciones de la sociedad civil, porque estas no tienen acceso a algunos resortes que mueven los elementos relevantes de la estructura (subsidios de desempleo, seguro social, pensiones, hospitales, educación, etc.) De hecho la atención que presta la sociedad civil es la más importante hoy día en España en la atención de estos colectivos. Es de justicia que se las favorezca como instrumentos que son de toda la sociedad para aliviar o resolver el problema

\section{La estructura socioeconómica, el modelo de sociedad}

La clave para cambiar la sociedad presente desde las raíces hacia arriba es cambiar o el énfasis que ponemos en la cantidad de posesiones a la calidad de vida. Por cantidad de posesiones entiendo el tener muchas cosas, las más posibles de la casi infinita variedad de productos, actividades y oportunidades que nos ofrecen los mercados, aunque no podamos disfrutar de todas ellas. Por calidad de vida entiendo tener un patrón de gasto y de consumo dictado por la disponibilidad de recursos económicos y limitado por la capacidad real de disfrutar de las cosas 
esenciales de la vida. Es decir, vivir disfrutando, con paz y serenidad de espíritu, las cosas que podamos conseguir para sentirnos satisfechos sin perder la tranquilidad. Es casi el ideal epicúreo de la aurea mediocritas.

El peso de este cambio está en la educación y en ejemplo. Hay que comenzar - y continuar - en el seno de las familias, porque allá es donde se siembran los valores, los criterios para obrar rectamente, pero también los prejuicios. En las familias se aprende tanto el desprendimiento y la solidaridad como el amor al dinero y el deseo de emular a los demás en el consumo. La escuela debe ser la continuación de la casa, cuando en la casa se aprende la rectitud económica. Allí no se debe oír nada que suene como alabanzas del individualismo, la emulación y el triunfo de los más fuertes. Y lo mismo se diga de la iglesia.

Puesto a educar para cambiar el modelo, tenemos también que educar para sacudir la pasividad económica de caracteriza a nuestros conciudadanos, que se portan como si estuviéramos condenados rígidamente a vivir como nos lo imponen los intereses económicos de las grandes empresas. No se puede aceptar ningún determinismo materialista, en el sentido de que el devenir económico esta todo determinado por la superioridad incontestable del modelo capitalista de economía de mercado. Hay que educar a las nuevas generaciones en la idea de que la historia está abierta, de que nada está predeterminado, que los hombres si tenemos voluntad y nos unimos en una acción colectiva podemos hacer cambiar cuantas veces sea necesario el rumbo de la historia y la trayectoria de la economía. Y para empezar hay que denunciar vigorosamente como el fraude intelectual que es el pensamiento único dominante en las cuestiones vitales sobre la organización y el funcionamiento de la economía y la sociedad.

Cultura de la moderación. Hay que educar en la moderación en el estilo de vida. Es difícil, pero no imposible, si se persevera y se forma opinión. Eso implica una rebelión masiva contra los patrones actuales de producción y de consumo de bienes y servicios, exaltando otros valores y usos posibles de las fuerzas y recursos materiales (formación, cultura, contemplación, disfrute, ocio, creación artística). La lógica económica pide, para no destruir empleo masivamente, el gradual desvió del consumo y la inversión hacia los bienes públicos o los nuevos bienes y servicios privados que fomentan y garantizan la calidad de la vida.

Siempre en la línea de la educación ciudadana para enfrentar los retos del futuro es necesario tomar conciencia del poder de los consumidores para controlar los mercados y las condiciones en que se producen las mercancías que adquirimos aquí o en el extranjero. Las grandes empresas multinacionales tendrán toda la capacidad 
que se quiera para promover sus ventas, seducir al consumidor, innovar y ofrecer nuevas maravillas, pero al final de cuentas tienen que vender, y si no venden se arruinan, necesitan de gente como tu y como yo que les compre sus zapatos, sus ordenadores, sus programas, sus telefonillos, sus tarjetas de crédito etc. y que los usen etc. En definitiva el consumidor es el rey, aunque esta afirmación valga del colectivo de consumidores, no de cada consumidor individual y aislado, que suele ser arrollado por las mareas de la moda y la emulación. Tenemos que tratar de influir el sistema desde la esfera en la cual los ciudadanos realmente tenemos un resto de poder: en el consumo. Desde el consumo podríamos crear una protesta ciudadana contra la imposición de modas, marcas, ídolos, formas de vivir que no son racionales ni solidarias. La dificultad para ello está, naturalmente, en organizar una acción colectiva de consumidores suficientemente numerosa y decidida como para afectar los ingresos de las empresas. Los costos y beneficios de organizar estas acciones colectivas no se compensan. Las acciones son costosas para un beneficio ni muy grande ni muy evidente para cada persona individual. Sin embargo, las nuevas tecnologías nos ofrecen nuevos medios de movilización y organización. Ya hemos visto varias acciones colectivas, las protestas contra la OMC en Seattle y contra el FMl y el BM en Washington y Praga, como ahora contra la Comisión en Niza, que han sido organizadas sobre la base de las posibilidades que ofrece el Internet.

El poder de los consumidores se están ejercitando en la extendida practica de la banca ética (no invertir en empresas que conculcan, directa o indirectamente, los derechos humanos) y en el comercio justo, que trata de soslayar la explotación de los pequeños productores de productos primarios como el café, por ejemplo. Otra muestra de poder que ha tendido efecto en varias ocasiones ha sido el boicotear productos concretos en situaciones particulares. La gente tiene más poder de lo que cree.

\section{Conclusión}

El futuro ha comenzado. Eso siempre se puede decir, porque el futuro siempre está sembrado en el presente. La siembra de desigualdad está siendo muy abundante en estos tiempos. De la misma manera, el individualismo y la avaricia se están lanzando a boleo. Eso sólo puede generar tempestades. Por otro lado la gente, o por lo menos, una buena mayoría siente desazón y descontento con el dominio de lo burdamente material y busca en valores espirituales, religiosos o no, un refugio, que no una alternativa, al modelo económico opresor. Poca gente, sin embargo, 
piensa en alternativas a la economía de mercado pura y dura. Incluso los más radicales contestatarios sólo saben criticar y demoler. No tenemos constructores, lideres políticos que esbocen o propongan un nuevo diseño de sociedad. Porque para que surjan estos líderes no hay interés, ni hay incentivos, ni recursos disponibles. Cuanto menos se piense en ello, mejor para el statu quo, que bastante problemas tiene para mantener la cara de humanista. Nos espera una larga travesía. ¿2Quién ayudará al pueblo escogido a atravesar el desierto? 